\title{
Social Inequality, State-centered Grievances, and Protest: Evidence from South Africa
}

\section{Alexander De Juan' and Eva Wegner ${ }^{2}$}

\begin{abstract}
What role does horizontal social inequality play for political protest in middleincome countries? We argue that public social service provision is an important driver of state perceptions. When a state fails to deliver services in an equitable manner, trust in institutions erodes and protest becomes more likely. We use a mixed methods design to investigate this argument in South Africa. First, we combine police event records with census data to estimate correlations between service inequality and protests. Second, we draw on an opinion survey with 27,000 respondents to investigate the suggested mechanism linking social inequality to protest through political attitudes. Third, we focus on qualitative protest accounts in two areas identified by a matching approach to assess the plausibility of our quantitative findings. Throughout these analyses, we document a robust association between horizontal social inequality and protest.
\end{abstract}

\section{Keywords}

protest, basic services, South Africa, legitimacy, grievances, horizontal inequality

'GIGA German Institute of Global and Area Studies, Hamburg, Germany

${ }^{2}$ School of Politics and International Relations, University College Dublin, Belfield, Ireland

\section{Corresponding Author:}

Alexander De Juan, GIGA German Institute of Global and Area Studies, Neuer Jungfernstieg 2I, 20354 Hamburg, Germany.

Email: dejuan@giga-hamburg.de 


\section{Introduction}

In August 2015, the city of Beirut was rocked by waves of protest: "We want power, we want water, we don't want rubbish in the streets. We want these politicians to get lost" (Al-Araby 2015). Similar claims were made when protests erupted in dozens of Brazilian cities in 2013: "Delivering on growth and employment is no longer good enough. Voters will increasingly hold their leaders accountable to improve the quality of public services such as health, education, transport and crime prevention" (Garman and Young 2015). The so-called service delivery protests have also become increasingly frequent in South Africa: "After 20 years, after the failure to address specific demands, the dissatisfaction is becoming generalized" (Serino 2014).

These examples illustrate three important points: First, they highlight the relevance of basic service provision - such as sanitation or electricity - as trigger of protest. Second, public service-related anger has strong potential to transform into more general political grievances regarding government accountability and responsiveness. Third, public service protests play a prominent role in countries such as Lebanon, Brazil, and South Africa in which citizens enjoy relatively high service levels compared to the population of poorer countries.

In this article, we argue that service inequality represents an important but largely neglected source of grievances in middle-income countries. Although recent research on protest and violence highlights the role of "horizontal inequalities" across regions and groups, most studies focus on economic and political inequality and largely neglect a third crucial dimension: horizontal social inequalities. According to Frances Stewart, horizontal inequalities are multidimensional: they comprise political, economic, and social elements. The first refers to political participation. The economic dimension covers the distribution of assets, income, and employment. Horizontal social inequalities refer to unequal social outcomes such as life expectancy, infant and child mortality, educational attainment and access to services across groups that differ in terms of geographical, behavioral, language, or physical characteristics (Stewart 2000, 2002).

We argue that this latter type of inequality is particularly relevant in countries where aggregate socioeconomic development is relatively high. In contrast to lowincome countries, middle-income countries have typically seen considerable socioeconomic improvements with the state becoming more noticeable as an agent of development in people's lives. With increasing resources, states typically increase investments into public service systems. The broadening of development priorities in national discourses creates expectations among the poor. Persisting service inequality provides a blatant sign to the populations that the state is not able or willing to meet these expectations in an equitable manner. This can not only trigger protest about services but also undermine state and government legitimacy and, by extension, increase the general willingness to protest. This does not mean that horizontal social inequalities may not also be relevant in high- or low-income countries, but we assume that middle-income countries combine characteristics that 
make them particularly prone to protests emanating from service inequalities: high, or increasing, expectations coupled with ineffective delivery.

We investigate associations between service inequality and protest in one specific middle-income country: South Africa. We draw on three main sources for our quantitative and qualitative analyses: first, we combine detailed data on crowd control events from the South African Police Service's Incident Registration with information on service inequality computed from the 2001 and 2011 South African population censuses to estimate correlations between horizontal social inequality and protest at the level of the country's 1,116 police districts. Second, we draw on a massive opinion survey with more than 27,000 respondents undertaken by the Gauteng City-Region Observatory (GCRO) in 2013 to investigate the suggested mechanism linking horizontal service inequality to protest through decreasing political trust. Finally, using a nearest neighbor matching approach, we identify two comparable administrative units in the Gauteng province to further assess the plausibility of the mechanism. Throughout the three empirical approaches, we find consistent evidence for a substantive association between service inequality, state perceptions and protest in line with our theoretical argument.

Our article contributes to research on the role of inequality in protest in two main respects: first, we propose and find evidence for a mechanism that links horizontal social inequality to protest: people blame the state for service deprivation which undermines confidence in state institutions and increases willingness to participate in protest against the state more generally. Second, we develop an argument as to why horizontal social inequalities are likely to be more relevant drivers of protest in middle-income countries than economic inequality or measures of absolute deprivation. We empirically demonstrate that the effects of service inequality do in fact outperform conventional measures of poverty and income inequality as predictors of protest highlighting the need for a broader-based conception of relative deprivation in analyses of protest.

\section{Previous Research and Findings}

Two contending perspectives dominate the debate on factors driving protest and violence: grievance-based explanations highlight motives for mobilization such as absolute and relative deprivation. The opportunity-focused approach, on the other hand, stresses costs and prospects of collective action. The following paragraphs briefly review standard arguments and empirical findings on both perspectives. ${ }^{1}$

The grievance-based perspective has its roots in social psychology. It highlights that effective mobilization is likely to occur when people feel deprived and frustrated with the status quo. In particular, feelings of deprivation and frustration are created if there is a gap between people's expectations and their actual achievements. Expectations may be formed in different ways: when individuals compare their own economic, political, or social situation with that of other individuals within their in-group; when they compare their own group's status with that of other 
groups; or when they compare their current situation with previous ones (Runciman 1966). Feelings of relative deprivation then provide powerful motives for collective action (Gurr 1970). Although a large of body of research in social psychology supports the explanatory power of relative deprivation for a variety of outcomes (see overview in Smith et al. 2012), empirical studies outside the lab have largely failed to uncover a direct and systematic relation between deprivation and conflict or protest (see Collier and Hoeffler 2004; Fearon and Laitin 2003; DiPasquale and Glaeser 1998, among others).

These findings have contributed to the rise of opportunity-focused explanations. Most notably, critics of grievance-related arguments stress that grievances are just too widespread to explain comparatively rare instances of political mobilization (Oberschall 1978; Tilly 1978; Skocpol 1979). The general argument is that costs, opportunities, and the efficacy of mobilization rather than grievances explain variation in the occurrence of protest with research focusing on factors such as government openness, state capacity, or the resources and strategies of social movements (see overviews in Meyer 2004; van Zomeren, Postmes, and Spears 2008). A number of empirical studies support the argument that political opportunities and resource availability play an essential role in the occurrence of violence and protest (see Collier and Hoeffler 2004; Fearon and Laitin 2003, among others). Yet, again, empirical results are far from painting a clear picture (see Meyer 2004).

Several authors argue that conceptualization and measurement rather than faulty theoretical premises may account for the lack of clear evidence on any of the two major theoretical arguments (see, e.g., Meyer 2004; Buhaug, Cederman, and Gleditsch 2014; Østby 2013). In this article, we will follow up on and attempt to improve the theoretical clarity of grievance-centered explanations. This specific focus does not mean that we dismiss the role of opportunity and feasibility but that we base our key argument on the assumption that variation in social horizontal inequality can account for variation in protest occurrence under similar political opportunity structures.

It appears indeed to be the case that measurement is a source of diverging findings in grievance research. Much of the research that finds no effect of deprivation on political mobilization measures deprivation either in absolute terms (e.g., a country's poverty rate) or in terms of interpersonal inequality, whereas findings in social psychology show that intergroup inequalities are more likely to generate collective action (see Smith et al. 2012). More recent studies on protest and violence in the grievance perspective have therefore started to focus on "horizontal inequality" (Stewart 2000, 2002) between regional, ethnic, or religious groups rather than on "vertical inequality" between individuals. Such horizontal inequalities can come in various forms, relating to political participation, economic conditions, or social conditions in terms of access to basic services (Stewart 2002). Emerging empirical studies on horizontal inequality have focused on political and economic deprivation finding indeed that it can explain variation in the occurrence of collective action (see, e.g., Buhaug, Cederman, and Gleditsch 2014; Murshed and Gates 2005; Østby 
2008). In contrast, the role of a third dimension of horizontal inequality, namely, variation in the access to basic social services, has received little attention in empirical research thus far.

Some recent studies on protest and violence indicate that deprivation of statesponsored public basic services such as electricity, water, or education may constitute a relevant source of protest event though these papers focus on absolute measures of delivery (e.g., Cornell and Grimes 2015 on Latin America, and De Juan and Pierskalla 2014 on South Sudan). To the best of our knowledge, only one previous study has explicitly dealt with social inequality in an empirical study: Østby (2008) finds inequality in terms of education to be relevant for mobilization. She focusses, however, on civil war rather than on peaceful and violent protest.

\section{Grievances, Blame Attribution, and Protest}

With this study, we want to contribute to research on horizontal inequality. Specifically, we want to highlight the role of social inequalities in terms of relative deprivation from state-sponsored services as an essential driver of grievances and collective action. Drawing on social psychology and social movement research, we argue that among the two suggested material dimensions of horizontal inequalitieseconomic and social - the latter should be considered more conducive to collective action in middle-income countries because the state is more readily blamed for this type of inequality.

\section{Links between Grievances and Protest}

Our starting point is the observation of a conceptual leap between standard deprivation measures and engagement in protest. Deprivation has mostly been operationalized with absolute poverty and development measures, individual-level income dissimilarity (i.e., the Gini index), and-more recently-proxies for group-level economic inequality (see Buhaug, Cederman, and Gleditsch 2014, for a systematic discussion). Protest, however, predominantly targets the state as the central object of claims (van Dyke, Soule, and Taylor 2004; Walker, Martin, and McCarthy 2008; McAdam, Tarrow, and Tilly 2001). It is not evident, how exactly economic individual, interpersonal, or intergroup conditions are linked to state-society conflict as manifested in popular protest against local or national governments. If people are poor (or poorer than others), why should they express their grievances in political protests that address state actors and institutions? In short, we argue that this approach lacks an explicit theory about the mechanisms by which such economic conditions translate into state-centered grievances that then trigger protest activity targeting the state.

Closing this theoretical gap requires additional assumptions on blame attribution that are rarely explicitly addressed by empirical studies on peaceful and violent protest. Research on social movements show that individuals and groups are more 
likely to protest when they can attribute blame for a problem to a clearly identifiable source and when they can identify actors or institutions capable of redressing their grievances (Benford and Snow 2000; Gamson 1975). This implies that for economic deprivation actually triggering protest against the state people must be convinced that the state is responsible for income inequality and that the state is able to end it (Javeline 2009). Such a link receives, however, little support by social psychology research. A number of studies demonstrate that many people either accept personal responsibility for their economic situation or attribute it to fundamental structural conditions or highlight fate, bad luck, or transcendent causes rather than to state actors, institutions, or policies (Ige and Nekhwevha 2012; Narayan-Parker 1997; Shepelak and Alwin 1986; Kluegel and Smith 1986). Such diffuse and fatalistic blame attribution creates feelings of powerlessness and inevitability reducing rather than increasing people's sense of injustice and willingness to mobilize (van der Toorn et al. 2015; Pellicer, Piraino, and Wegner 2014; Javeline 2009). A much smaller share of the population tends to directly blame the government for its absolute or relative economic deprivation (Smith and Stone 1989; Iyengar 1989; Narayan-Parker 1997).

These findings underscore the theoretical gap between general economic measures of deprivation and political protest. Frustration resulting from poverty and unemployment may create anger against state institutions in some cases. In many others, however, blame is attributed in a way that is not conducive to mobilization.

\section{Service Inequality and Protest}

Our main theoretical argument highlights that service inequality can undermine state and government legitimacy and thereby increase the likelihood of protest. This argument rests on the contention that the dissatisfaction with the service delivery is more likely to produce anger against state institutions than dissatisfaction with people's economic situation. We argue that this is the case for two main reasons. First, basic services constitute a form of direct interaction between the individual and the state's institutions and actors" (Brinkerhoff, Wetterberg, and Dunn 2012), and the state is more easily identified as the main culprit of people's deprivation of state-sponsored services. As argued in the Introduction section, this holds particularly true for middle-income countries that explicitly portray themselves as "developmental states" with a strong public agenda of improving people's living conditions through the broad-based expansion of basic services.

Second, contrary to eradicating poverty, providing access to services is a rather technical and visible act, related to the construction of infrastructures and the deployment of personnel. Consequently, solutions to service deprivation are much more easily identified. People see schools being built or neighborhoods being connected to electricity grids in some areas, testifying to the state's general capability of improving access to services and reinforcing frustrations 


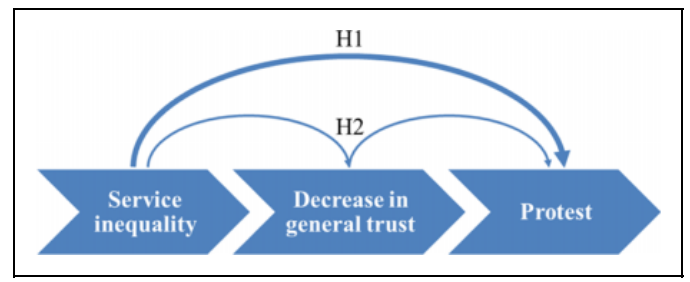

Figure I. Argument and hypotheses.

related to the state's negligence of other areas. Again, feelings of injustice are being reinforced by situations typical to many middle-income countries where states announce the expansion of basic services, raising expectations but then being unable to serve the whole population (see De Juan and Pierskalla 2014, for a similar argument).

Importantly, survey-based studies on the relationship between service delivery, poverty, and political perceptions lend credibility to our basic argument. Research shows that the access and quality of basic services are often strongly correlated with people's assessment of state institutions. A study on Colombia, for instance, indicates that perceptions of improvements in government service delivery have a positive impact on both trust and approval ratings of local government representatives (Guerrero 2011). Similarly, survey research on Nepal finds a service delivery index to be highly and positively correlated with measures of political trust (Askvik and Dhakal 2011). In contrast, these studies do not find consistent effects of poverty or other forms of economic well-being on trust or government perceptions.

Thus, these studies suggest a specific indirect causal mechanism through which service deprivation increases the likelihood of protest. Apart from creating frustrations that may directly lead to actual "service delivery protests," service deprivation can negatively affect people's more general attitudes toward the state and increase the state's overall "vulnerability" to mobilization and protest. A state that is held responsible for not effectively caring for the most basic needs of the population will also be more easily identified as the main culprit for other grievances. Any protest frames blaming the state for lack of responsiveness and accountability will therefore resonate more effectively in the light of people's more general assessment of state institutions, thereby increasing the overall probability of resulting in protest against the state.

Figure 1 schematically represents our argument and the hypotheses we propose for empirical investigation. First, our main hypothesis is that the probability of protest increases with higher levels of horizontal service inequality (Hypothesis 1). Second, we propose a hypothesis about the mechanism by which horizontal service inequality leads to higher protest: higher levels of horizontal service inequality increase the probability of distrust in state institutions which increases the likelihood of protest (Hypothesis 2). 
We investigate these hypotheses using a mixed method approach that combines the analysis of administrative data, of public opinion data, and of qualitative protest accounts. Although we examine the first hypothesis across all three analyses, each of them has additional strengths. In the analysis based on administrative data on protests and socioeconomic characteristics, we are additionally able to evaluate the relative role of social (service) inequality and economic inequality as predictors of protest. Moreover, using a wealth of administrative data, we are able to account for a number of potential confounding factors. In the analysis based on public opinion data, we are able to explore the two correlations we would expect from Hypothesis 2, namely, that inequality correlates positively with government satisfaction and that government satisfaction correlates negatively with protest. In the final analysis of protest accounts, the entire mechanism in Hypothesis 2 is evaluated, namely, whether protesters link protest engagement to dissatisfaction with government as a result of service inequality. We believe that not only investigating the main hypothesis from different angles but also making use of the relative strengths of the respective data formats is a useful application of a mixed methods perspective. Before we proceed to introduce the data and detailed empirical strategy of our analysis, the next section introduces our empirical case.

\section{South Africa}

We investigate our hypotheses using South Africa as empirical example. This case is particularly well suited for our analysis in two main respects. First and foremost, we consider South Africa a "typical" case with respect to the puzzle we seek to investigate: it is a middle-income country with a comparatively high level of aggregate socioeconomic development compared to regional averages, having one of the highest gross domestic product (GDP) per capita on the African continental mainland (see data from World DataBank). At the same time, however, South Africa has also experienced a particularly high number of peaceful and violent protests. According to the "Social Conflict Analysis Database" (Salehyan et al. 2012), only Nigeria, Egypt, and Libya display higher counts of violent and peaceful protest events over the past decade. Thus, focusing on the case of South Africa allows us to investigate what factors explain high levels of protest under the aggregate conditions of relatively high economic development and growth.

The other African countries that display the specific combination of aboveaverage GDP per capita and above-average numbers of protest are Tunisia, Libya, Algeria, Morocco, and Egypt. Although all of these countries may constitute interesting cases - most notably with respect to investigating the drivers of protest waves in 2011 - reliable and fine-grained socioeconomic and protest data are impossible to obtain for these countries. ${ }^{2}$ Indeed, as we will discuss below, our second main reason for focusing on South Africa is the availability of highly disaggregated information 
on service delivery, violent, and peaceful protest as well as on public opinion that is particularly rare in its level of detail and quality.

\section{Service Delivery and Protest in South Africa}

Present-day South Africa inherited massive levels of inequality from the Apartheid era. During Apartheid, the government put most resources in "white areas" that had service delivery levels akin to Western Europe with only little investment in black neighborhoods that lacked access to health care and education and basic services such as water, electricity, or sewerage. This was especially acute in the so-called homelands, into which the Apartheid regime forcibly moved African blacks not required for the white economy (Horrell 1973).

When Apartheid ended in 1994, citizens had high expectations about the economic payoffs of the political transition. Since then, the country's massive investment in service delivery improved absolute access to basic services across South Africa. According to the latest population census in 2011, the biggest improvements were in terms of electricity, with 85 percent of households having access compared to 60 percent in 1996. Access to water and sanitation also increased, with around 70 percent and 60 percent of households having access to these two respective services in 2011 compared to 60 percent and 50 percent in 1996 (see SANews.gov.za 2013).

In spite of the government's explicit development agenda, social protest against the lack of services has gained in importance after the end of the Apartheid regime. Over the last decade, a high number of violent and long-lasting service delivery protests attracted a lot of attention by researchers and the media. As most of the literature is qualitative and uses newspaper sources to document-specific protests (such as, e.g., Booysen 2007; Alexander 2010; Atkinson 2007), the motives underlying these protests have not been systematically studied. In turn, a variety of reasons for protest has been suggested including poor service delivery, lack of accountability, unfulfilled expectations, and comparative poverty and inequality of access to services.

Some of the South African protest literature seeks to quantify protests over time, relying either on the coding of media articles (Hirsch 2010; De Visser and Powell 2012) or on aggregate figures from the police that are reported occasionally in replies to parliamentary questions (e.g., Alexander 2010). Three trends emerge from this literature: (1) protest has been increasing since the mid-2000s, (2) the share of violent protests has been increasing, and (3) service delivery protest correlates positively with service delivery levels.

The joint increase in access to services and protest in South Africa appears puzzling at first sight. Certainly, the government has invested substantial resources into the rolling out of basic services, and these resources have produced tangible increases in the share of connected households. Why, then, have we seen such a substantial increase in protests? The explanation explored in this article focusses on horizontal inequality in service delivery. 


\section{Horizontal Inequality in South Africa}

Horizontal inequality is a relational concept that assumes that people tend to identify with specific regional, ethnic, or religious groups and compare their own group's status to that of other groups (Stewart 2002). Thus, we need to define what constitutes a "relevant" group identity and what defines the reference group against which people contrast their group's situation. For South Africa, we opt for a spatial definition of groups. We take the local communities as groups and assume their reference point to be neighboring communities/neighborhoods. Although "race," that is, the population groups defined by the Apartheid regime (African Black, colored, Indian/Asian, and white) is doubtlessly a salient identity dimension in South Africa, we believe that our small-scale groups are a more useful measure. First, race is by no means the only relevant identity dimension with surveys showing that local communities in South Africa are important sources of identity. For example, the latest World Values Survey shows that 90 percent of South Africans agree or agree strongly with the statement "I see myself as part of my local community." Second, because neighborhoods are generally racially homogenous and subplace boundaries thus coincide with "racial boundaries," our measure is additionally able to capture racial inequality in access. ${ }^{3}$ Lastly, analyses of census data have shown that intrarace inequality has been increasing strongly in post-Apartheid South Africa while inequality between races has been decreasing (Leibbrandt et al. 2009). Thus, if we were focusing on race-based inequality alone, we would certainly miss an essential dimension of inequality-uneven access to services across neighborhoods with similar race composition.

We rule out comparisons across more distant regions because, as argued above, we believe that exposure is essential in explaining how deprivation creates grievances. Inequality will create frustrations among the disadvantaged only if they are directly exposed to the privileges of others. As Marx highlights "A house may be large or small; as long as the neighboring houses are likewise small, it satisfies all social requirements for a residence. But let there arise next to the little house a palace, and the little house shrinks to a hut" (Marx [1847] 1935, cited from Smith et al. 2012).

\section{Correlations between Inequality and Protest}

We begin by examining the broad correlations between horizontal social inequality and protest in South Africa. Peaceful and violent protest is measured with data on crowd control events from the South African police. Inequality in service delivery and income, absolute levels of service delivery, and a number of control variables are constructed from subplace tables of the South African population census 2011. All data are aggregated at the level of the police district $(N=1,116)$. We have chosen these districts as main units of analysis for pragmatic rather than for any substantive reasons. Police districts are not meaningful for our analysis in 
themselves, but they constitute the smallest level at which most protest events are being reported. We address potential modifiable areal unit problems, emanating from our specific choice by replicating our main analysis on the level of individual households (see Linking Inequality to Protest section below).

\section{Outcome Variables}

We obtained detailed data on crowd control events from the South African Police Service's Incident Registration Information Service (IRIS). Data in this database are entered by local police after gatherings involving more than fifteen participants. The database contains the data and location of the event as well as information on whether the event was peaceful or violent. In addition, the database contains an event coding by the South African police (e.g., "labor dispute" or "dissatisfied with housing") and detailed notes on the intervention. Most of the indicated locations are the names of police districts, the remainder was recorded at a higher or lower level (either municipalities or census subplaces). ${ }^{4}$ Peaceful events are those involving "cooperation with the convener," in events classified as violent, police forces "intervene to make arrests or [...] use force" (Minister of Police, Republic of South Africa 2010).

We only use IRIS data on events in the three years following the 2011 census. We recoded the data into four broad categories, namely, protest related to service delivery, elections, identity, or generally against the state. The first comprise all events related to general dissatisfaction with basic services, service charges, or the suspension of services (2,782 events between 2011 and 2013). The second category refers to events in the context of voter registration, election campaigns, or actual votes (1,300 events). The third event type includes events related to ethnic and racial conflict as well as to Xenophobia more generally (136 events). Finally, we aggregate all events that are directed against state policies and actions broadly defined: for example, attacks on state security forces, demands of resignation of councilors, resistance against court decisions, or against the educational system (2,024 events). In addition to the total number of violent or peaceful events, the outcome variables thus consist of the number of events in these categories. Because of the highly skewed distribution of events, we use the log of events in the main analysis. Results are, however, robust to using the absolute number of protests instead.

We believe that these data are particularly well suited for an analysis into the role of grievances in motivating protest. The data set contains a high number of low-intensity events due to the low coding thresholds of a minimum of fifteen participants per event. Consequently, factors highlighted in opportunity-centered explanations of protest (i.e., the repressive capacity of the state) are certainly less relevant in determining spatial patterns of protest requiring little organizational capacities.

Our confidence in data reliability is quite high. If political incentives existed, these would go in the direction of underreporting. However, the massive number of events reported in these data makes this rather unlikely. Importantly, there are no 
clear incentives for misreporting from the side of a particular police district, that is, misreporting in a nonrandom way. Moreover, the protest figures have repeatedly been requested in parliamentary questions and thus receive a certain degree of political scrutiny.

\section{Explanatory Variables}

We focus on service inequality as key explanatory variable. It is calculated from the 2011 South African population census. We consider four types of access to services: access to electricity (electricity as main source of lightning), access to sanitation (flush and ventilated improved pit toilets), access to trash removal (with the municipality collecting trash once per week), and access to water (piped water inside the house or yard). We first create a measure of absolute service delivery levels gauged by the share of households in a given police district having access to such improved services. Access to these services is highly correlated $(r>.5)$, and we opt for a service index that is the mean of these four access variables. ${ }^{5}$

We measure inequality in service delivery between census subplaces constituting a police district using a "dissimilarity index" (Duncan and Duncan 1955). The dissimilarity index is typically used to gauge the extent of residential race segregation but has recently been proposed to measure inequality in access to water and sanitation ( $\mathrm{Yu}$ et al. 2014). It is calculated as follows:

$$
D_{i}=\frac{1}{2} \sum_{i=1}^{N}\left|\frac{w_{i}}{W}-\frac{n w_{i}}{N W}\right|,
$$

where $w_{i}\left(n w_{i}\right)$ is the population with (without) access to services of the $i$ th area, in our case a census subplace, and $W(N W)$ is the total population with (without) access to services of the larger geographic entity for which the dissimilarity index is being calculated, in our case the area of a police district. Its value can be interpreted as the share of people that would have to move in order to gain an equal distribution. It takes a value of 0 if the different subplaces making up the larger area have the identical share of access to services and a value of 1 if access is fully uneven. ${ }^{6}$

The resulting variables for the inequality in the delivery of electricity, sanitation, water, and trash removal have means around 0.5 and standard deviations of around .25 (see Table A4.1 in the Online Appendix for descriptive statistics of all main variables). Similar to the absolute service delivery variables, the dissimilarity variables are highly correlated and we also use their mean as main explanatory variable.

All regressions include a number of control variables. Unless otherwise indicated, the variables are constructed from the 2011 census data. Most importantly, we control for income inequality as we want to compare the relative impact of economic inequality and service inequality as drivers of protest. In order to use a measure of income inequality that is directly comparable to our measure of service inequality, 


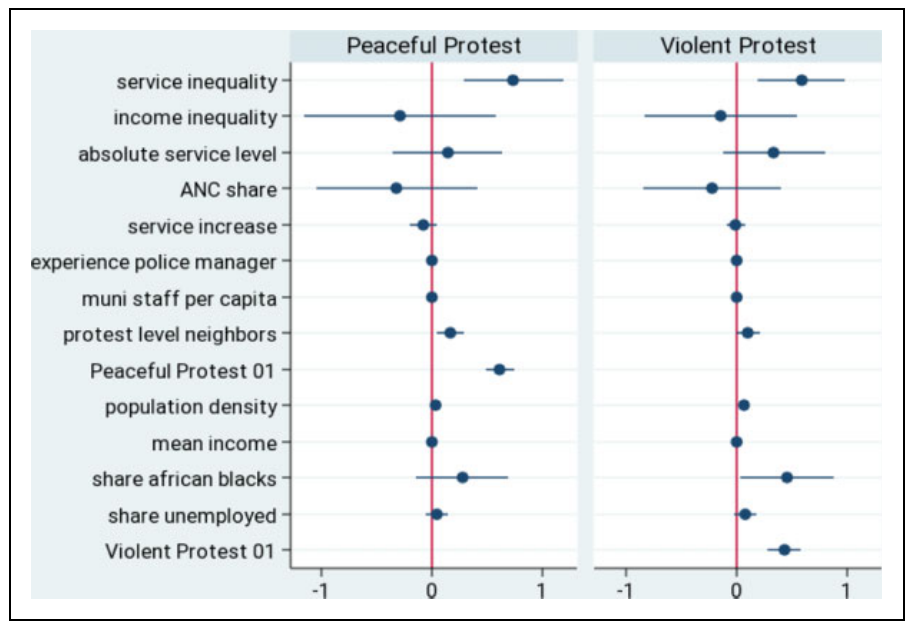

Figure 2. Forms of protest, 20I I-20I3. Standard errors clustered at the municipality, additional controls: province dummies.

Source: Incident Registration Information Service, South Africa Police Data.

we compute the dissimilarity index for household income, defining as poor households those not having income or being in the lowest income bracket - in total about 20 percent of South African households.

Other control variables are protest in neighboring spatial units, previous protest in the district, changes in service delivery between 2001 and 2011, unemployment shares and mean income as additional measures of absolute deprivation, the share of African blacks per police district, and African National Congress support measured as the party's vote share of registered voters (calculated from the 2011 election results). ${ }^{7}$ We also include a measure of local state capacity measured by municipal staff per capita and the police manager's years of experience. ${ }^{8}$ Lastly, we control for population density $(\log )$.

\section{Results}

We perform ordinary least squares (OLS) regressions of (log of) protest on inequality in service provision. After excluding those police districts for which we were unable to compute a dissimilarity index and those where no events were recorded between 2011 and 2013, we remain with a sample of 877 observations. ${ }^{9}$

Figure 2 displays the results for peaceful and violent protest, Figure 3 displays the results by motive for protest (i.e., whether protests were related to services, the state, elections, or identity); the detailed results can be found in Tables A4.2 and A4.3 in the Online Appendix. The symbols display the point estimates, the lines show the 95 percent confident intervals. 


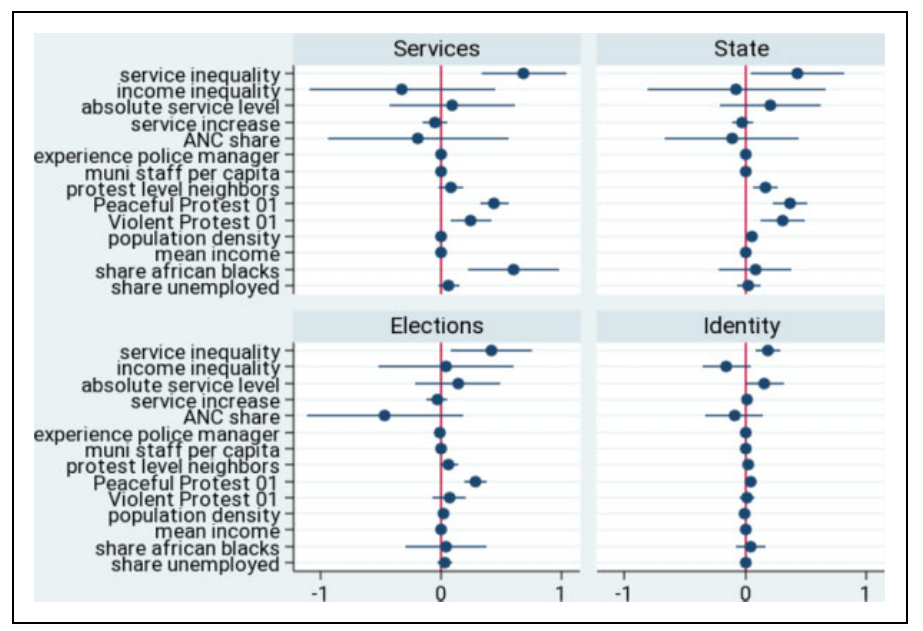

Figure 3. Protest motives, 20I I-2013. Standard errors clustered at the municipality, additional controls: province dummies.

Source: Incident Registration Information Service, South Africa Police Data.

The core insight from both figures is the importance of inequality in service provision for protest. More precisely, a ten percentage point increase in service inequality leads to a 7 percent increase in peaceful protests; for violent protests, the figure is 6 percent. Service inequality is most strongly associated with protests about services (with a ten percentage point increase in inequality leading to an around 7 percent increase in service-related protests). As hypothesized above, however, service inequality also matters for all other types of protest, suggesting that service inequality might indeed generate a broader sense of alienation from the state. In contrast, income inequality shows no consistent relationship with protests confirming that economic measures might not be strong drivers of political protest in South Africa.

Control variables mostly show the expected sign. The only other variablesbesides service inequality - that show a consistent positive and significant relationship with protest across all analyses are previous protest and in surrounding police districts possibly capturing additional aspects of protest capacity such as the presence of community leaders or organizations.

The main findings are robust to using police protest data from 2001 to 2003 (see Online Appendix A1) and to using a media data set on protest generated by the Institute for Security Studies in Pretoria (see Online Appendix A3).

\section{Linking Inequality to Protest}

We demonstrated a robust correlation between service inequality and the number of protests per police district. In a second step, we investigate whether these 
associations can plausibly be traced back to dynamics theorized above, namely, that service inequality undermines state legitimacy and that government dissatisfaction is a predictor of protest. For this purpose, we undertake an empirical case study of Gauteng province. The main rationale for selecting this specific province as a case mirrors that for the selection of South Africa as our country case. Gauteng is South Africa's richest province, which includes the cities of Johannesburg and Pretoria. At the same time, Gauteng has experienced the highest level of protest in South Africa. Thus, the case should be well suited for an analysis of the role of social inequality in driving protest. The following subsections introduce the data and summarize the findings.

\section{Data and Measurement-GCRO Survey Data}

We make use of a unique opinion survey undertaken and generously provided to us by the GCRO. The GCRO biannual quality-of-life (QoL) survey measures socioeconomic circumstances, attitudes to service delivery, psychosocial attitudes, and other characteristics. The QoL survey instrument contains a large body of items related to the households' socioeconomic living conditions as well as individual social and political attitudes.

We use the third and largest (in terms of sample size) wave of the QoL undertaken in 2013/2014 with a total of 27,490 respondents. The data set contains so-called small area codes that allowed us to match survey data to census information on the subplace level. In total, we consider 2,467 subplaces with an average of eleven respondents per subplace (minimum of 1 and maximum of 185). We capture absolute access to services by creating an additive index for respondents' individual access to water, electricity, sanitation, and trash removal based on the census data introduced above (sum of four binary variables, each representing the highest service category, namely, piped water in dwelling, connection to public electricity grid, flush toilet connected to sewage system, and regular waste removal from respondents' house).

To measure service inequality, we focus on the relative difference in access to services across neighboring subplaces - again, relying on the census data: for each subplace, we calculate the difference between the average service score of all of its first-level neighbor subplaces and its own service score. In order to normalize differences by absolute service levels of subplace clusters, we divide the resulting difference by the average service sores of the subplace and its neighbors. Each respondent was attributed the inequality score of her home subplace. Thus, the service inequality measure represents the relative availability of services in respondents' neighborhoods as compared to all surrounding neighborhoods. ${ }^{10}$ Using aggregate neighborhood measures rather than individual access to services, we conceptualize our explanatory variable in a way that reflects the general premises of horizontal, group-based arguments on deprivation. To ease comparison of estimations with the police district ones, the index is coded in a way that higher 
(positive) values signify a worse "inequality situation" from the respondent's point of view, meaning that he or she lives in a neighborhood that is worse off in terms service access than neighboring areas.

For attitudes toward the government, we use a QoL survey item asking for a respondent's level of dissatisfaction with the national government (Likert-type scale, 5 point). For protest participation, we use an item asking if the respondent participated in service delivery protests within the past twelve months prior to the interview. A total of 1,105 (4 percent) of the interviewees claimed having taken part in protests.

In line with our primary estimations presented above, we include a number of selected controls into our models. For absolute individual-level access to services, we calculate an additive index of access to improved services (electricity, water, sanitation, and waste removal) in line with our police station analysis, using respective GCRO survey items. For unemployment, we use respondents' self-declared employment status. For income, we use an additive asset index (possession of cell phone, bicycle, and car) instead of a generic household income question due to the high number of missing values in the income item (25 percent of the respondents refused to answer the question). Finally, we control for sex, age (and age squared), and population group (African blacks). In addition, all regressions include dummies for main places to control for any unobserved variation across these low-level administrative units.

\section{Correlations between Inequality, Political Attitudes, and Protest Participation}

We present the results of simple OLS regressions on our two main hypotheses: the first model reassesses our primary hypothesis on the individual level and estimates associations between horizontal social inequality and protest participation (detailed results presented in Table A4.4 in the Online Appendix). ${ }^{11}$ The next two models address our second hypothesis and reflect the suggested mechanism leading from service inequality to protest: thus, the second model estimates correlations between service inequality and political dissatisfaction, while the third model assesses associations between dissatisfaction and protest. All three models lend additional support to our two hypotheses (see Figure 4):

As expected, service inequality correlates positively with participation in protests. This finding mirrors the results on the level of police districts. Moreover, we find a statistically significant and meaningful correlation between service inequality and dissatisfaction with the government: the lower the respondent's neighborhood's service levels as compared to neighboring areas, the less satisfied are people with the national government. Finally, higher levels of dissatisfaction are also positively linked to participation in protest within the twelve months prior to the survey. Overall, results correspond to our theoretical argument that inequality of service delivery increases people's willingness to protest by generating more general political grievances that are directed against the state. 


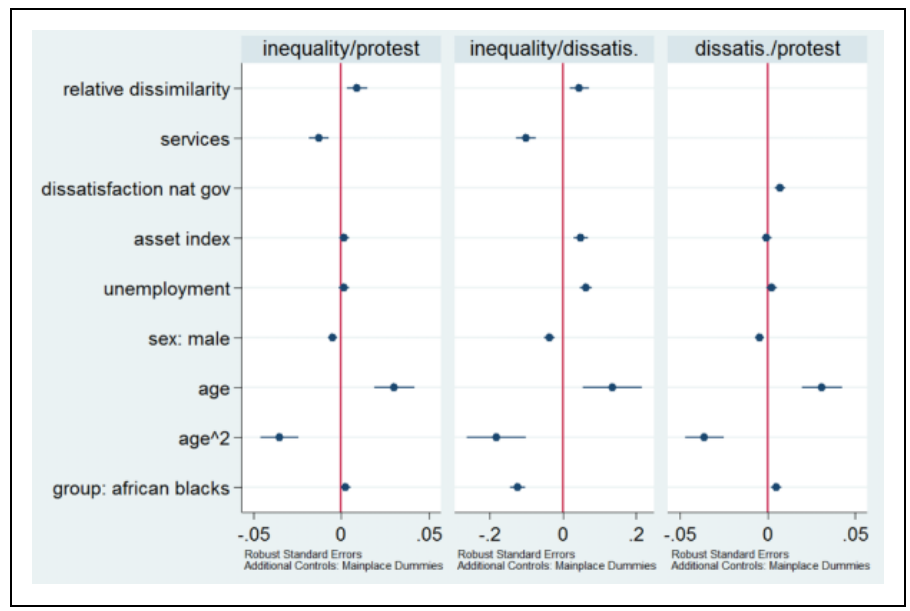

Figure 4. Gauteng City-Region Observatory: Government dissatisfaction and protest, $2013 / 2014$.

Turning to the control variables included in the model, we see that absolute service levels negatively correlate with protest propensity and dissatisfaction with the national government. Similar to our main models, findings on absolute economic deprivation are inconclusive as both unemployment and income are positively related to protest and dissatisfaction.

\section{Qualitative Comparison}

In a final step, we turn to a qualitative analysis to investigate if these correlations do indeed represent the mechanisms presented above. We draw on rich additional information contained in the police and survey data as well as newspaper reports to qualitatively analyze the plausibility of this mechanism. Considering that we have addressed a number of potential competing arguments on protest occurrence in the previous quantitative analysis (e.g., political affiliations, economic inequalities, or capacities for protest), we focus the qualitative section on investigating whether protest narratives do indeed refer to issues of horizontal social inequality.

We use a matching approach to identify our qualitative cases. Our approach corresponds to the most similar method (most similar systems design): we seek to identify two cases that are similar with respect to a number of potential confounding factors but that differ in terms of the main explanatory variable of interest. Thus, one of the two cases can be considered "treated" in terms of high level of service inequality while the other "untreated" one-in terms of low service inequality-is used as a control case (Seawright and Gerring 2008). ${ }^{12}$ We then investigate whether the presence of the treatment can plausibly explain observable variations of the outcome of interest. 
We use our Gauteng police-station data set as the total population of potential cases. Because the QoL survey was not designed to be representative at the level of police districts, we restrict the data to those police stations where the QoL survey data appear to be relatively representative in terms of employment, access to services, and race. ${ }^{13} \mathrm{We}$ identify the two police stations with the smallest Mahalanobis distance with respect to absolute service levels, the share of unemployed, the population density, the share of African blacks, and the municipality that the police stations are located in. ${ }^{14}$

The two police stations of "Diepkloof" (treated) and "Moroka" (control case) represent the best match of any treated and untreated case combination. Both are located in the Soweto area of Johannesburg (see Figure 5). Diepkloof has a dissimilarity index of .77 as compared to .32 in Moroka (see further characteristics of both cases in Table A4.5 of the Online Appendix).

\section{Service Inequality as a Driver of Protest in Diepkloof and Moroka}

Service inequality is indeed much more pronounced in Diepkloof than in Moroka (see Figure 6). Inequality is mainly driven by two particularly deprived townships: Mandela Village in the southwest (later renamed into Elias Motsoaledi) consists of mainly informal settlements. Zone 6 , located in the center of the station, hosts a number of hostels originally established by the Apartheid regime to house large numbers of single migrant workers with large dormitory spaces (Mafukidze and Hoosen 2008). These two deprived zones contrast with other much better-off areas, most notably the so-called Diepkloof extension in the northeast of the police district, characterized by large owner-built houses. It has substantially higher rents than other areas of Soweto, presumably, among other reasons due to the substantially better services (Rubin 2008). Most notably, according to Soweto residents, the area is home to influential personalities: "if there is a problem with service and they open their mouths, the whole of Soweto shakes" (Selzer 2012, 181). According to our data, no similar inequalities are observable in the Moroka station.

In line with our main findings, Diepkloof has experienced a substantially higher number of peaceful and violent protest events than Moroka throughout the period from 2000 to $2013^{15}$ (see Figure 5). The police event data provide information on the motives of protesters according to the police's own assessments. They also contain brief descriptions of events, which often include information on the protestors' own claims. A total of 22 out of 141 ( $\sim 16$ percent) peaceful protest events in Diepkloof have been linked to basic services according to the police's own categorization or according to information provided as protestors' claims. In Moroka, only a single event out of a total of twentyseven events ( $\sim 4$ percent) was related to service delivery issues.

Differences across cases are even more pronounced for violent protests. From 2001 to 2013, a total of twenty-five violent events have been registered in the two police stations under investigation - twenty-three of them in Diepkloof and two in Moroka. Among violent events in Diepkloof, more than half were explicitly related to service delivery issues, in Moroka, they were not. 


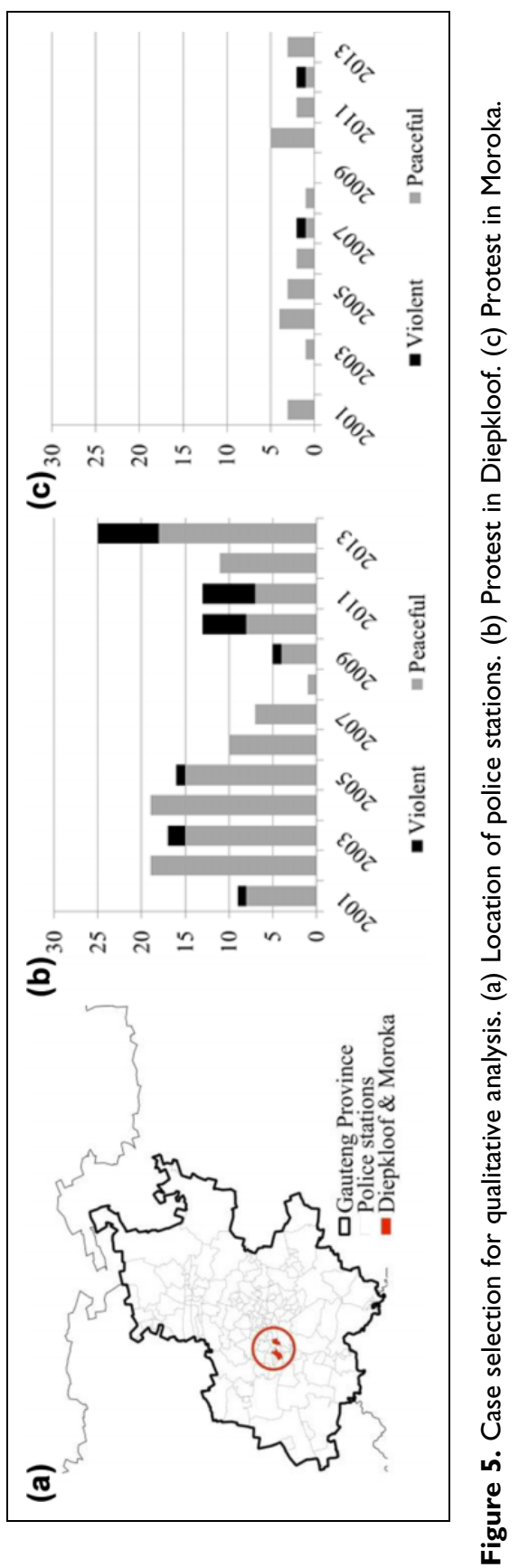




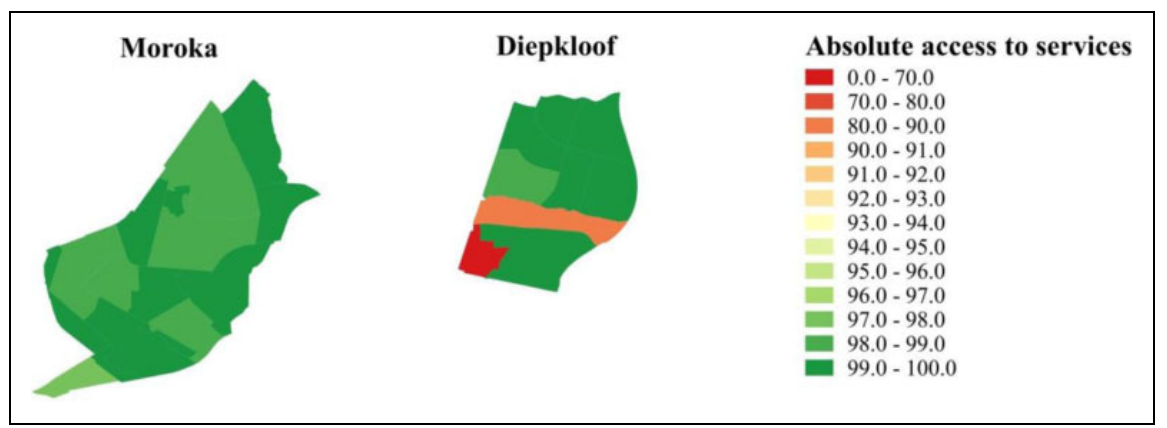

Figure 6. Absolute services in Moroka and Diepkloof, $201 \mathrm{I}$.

Qualitative reports on the Diepkloof townships of "Zone 6" and "Motsoaledi" further underscore the role of stark contrasts in service conditions compared to neighboring townships in fomenting grievances and motivating protests in these areas (Harsch 2011; Mabotja 2015). This is also reflected in local protest narratives: "We have no privileges like these councilors or the people across the street from us. [...] All I want is better sanitation, electricity, a house" (Mokati 2011). When protest erupted over inadequate sanitation, a resident stressed, "When I was growing up, we had to use the bucket to go to the toilet. That was in the $1960 \mathrm{~s}$.... We hear there are people in this country no longer using the bucket system. Why is it just us? It's wrong" (Bega 2014b).

Thus, in line with our theoretical argument, not only are levels of protest higher in Diepkloof as compared to Moroka. Protest motives also seem to differ across both police stations. In Diepkloof, grievances related to service deprivation play a much more pronounced role. Explicit accounts of service inequality underscore that protests are in fact triggered by social horizontal inequality.

\section{Services and Attitudes toward the State}

We have argued in the theory section that higher service inequality can not only directly lead to service-related protest but also create more general antistate grievance. Our two quantitative analyses have lent some support to this argument: service inequality correlates with a variety of protest events, not only with those clearly classified as "service delivery protests." The QoL analysis has found that high inequality increases the general dissatisfaction with the national government and that dissatisfaction is positively correlated to protest. This final empirical subsection aims at investigating the plausibility of the argument in the light of available qualitative information.

The QoL survey shows marked differences in between both police stations when it comes to people's general sentiments of being neglected and voiceless. Interviewees have been asked to express the degree of their agreement to the following statement, 
"People like you cannot influence developments in your community." In Moroka, around 60 percent of the respondents disagreed as compared to 30 percent in Diepkloof. Similarly, in Moroka, 56 percent of the interviewees disagreed with the statement "no one cares about people like me" as compared to 30 percent in Diepkloof.

Interviews from qualitative studies and newspaper reports demonstrate that people do link service issues to more general assessments of the political system and the responsiveness of the government: deprivation of services is seen as marginalization and deprivation of basic rights at the hand of the state, lack of democracy, and propoor orientation of the government (Khunou 2002). Participants in service delivery protests legitimize their actions with reference to lack of effective state action: "It's because they do not care about us [... ] people are so angry, no one can live like this, what did we vote for? They say they will go and burn the councilor's house if he does not respond" (Siyotula 2014). A resident of Diepkloof stressed, "I think democracy should allow for everyone access to basic needs [... ]. Because not everybody has access, I think democracy in South Africa has a long way to go" (Khunou 2002, 69). Similarly, in the context of service delivery protests in Diepkloof, "What have we and our parents been voting for? For a government that doesn't take care of our needs?" (Mtshazo 2013) or "If you're not with a certain party, then you are not eligible to get service delivery. There is no democracy here in Diepkloof" (Mokati 2011). Another Diepkloof protester went as far as stating that Apartheid times had been better, certainly signaling a very high level of alienation from the state. She explained her participation in a radical protest against poor sanitation stating that "The government doesn't want to fix anything [...] We can go upside down on our heads. We are talking but no one is listening. Things were better under Apartheid" (Bega 2014a). Focus group discussions undertaken by Netswera (2005) clearly reveal that many people in Soweto blame local and national politicians for making service promises in election periods without implementing real improvements afterward. Such service-related grievances contribute to nurturing more general antistate sentiments that increase the risk of peaceful and violent protest events not directly related to service issues.

\section{Conclusion}

Across data sources and methods, we find a robust relationship between horizontal social inequality and protest in South Africa. We moreover find evidence that the mechanism through which this relationship operates is that service inequality generates a general alienation from the state. Although these findings underscore the role of service inequality, it is also noteworthy that absolute service deprivation also seems to play an important albeit less clear role in generating negative political attitudes and increasing the likelihood of protest. In the administrative data analysis, we find no clear and significant relationship. When focusing on Gauteng with presumably higher quality services than in the rest of the country, we do find that absolute access to services influences political perceptions and protest participation. Taken together, these findings present a promising avenue for further 
research focusing on the role of the quality of state-sponsored services in generating protest.

Naturally, none of the results presented in this article can be interpreted causally as we could not rely on exogenous shocks to service inequality. However, we believe that the consistent findings we present across aggregate and individuallevel data across time, protest data source, and quantitative and qualitative analyzes lend a lot of credibility to the core findings. This finding highlights the need for more refined conceptualization and measurement of grievances in analyses of contentious politics. Our results show how purely income-based proxies can fall short of adequately capturing material frustrations which may lead to premature dismissal of grievance-based explanations of violent and peaceful protest. Going forward, a more careful consideration of economic state policies and state action beyond basic services may contribute to a better understanding of how grievances can translate into collective action against state actors and institutions. Similarly, the analysis of other types of horizontal social inequalities (e.g., variation in access to social transfer programs across groups) may yield important findings on the determinants of protest.

The South African case is certainly peculiar in at least two respects. The first is the Apartheid origins of present-day (service) inequality. Inequality arising from state-level race discrimination has particularly low legitimacy and enduring Apartheid patterns in service inequality could be leading to above average alienation from the state. The second is a strong elite discourse about the developmental state where the state takes explicit responsibility about service delivery, education, health care, and employment. In other words, the South African state self-identifies as core agent of development and failures in meeting citizen expectations could lead to particularly high levels of disappointment.

Nevertheless, we believe that the findings presented in this article can be of more general value. First, social inequality often has a spatial and/or group pattern where, for example, some ethnic groups have been favored in service delivery or slum dwellers in large cities without access to basic services live close to affluent neighborhoods. Second, many middle-income countries have at least a certain degree of developmental state philosophy. They act as agents of public services, provide some level of social security benefits, and have a relatively large penetration. It is a sensible assumption that citizens regard them as responsible for service inequality, lack of service provision, and service quality. Perhaps they do this to a lesser extent as their South African counterparts but probably to an extent sufficient for alienation from the state in case of persistent unequal treatment.

\section{Acknowledgment}

We thank Miquel Pellicer, Jan Pierskalla and Johannes Vüllers for their helpful comments on previous versions of the paper. Part of the data used in this paper is taken from the 2013 Quality of Life survey commissioned and generously provided to us by the Gauteng City- 
Region Observatory, a partnership of the University of Johannesburg, the University of the Witwatersrand, Johannesburg, and the Gauteng Provincial Government.

\section{Declaration of Conflicting Interests}

The author(s) declared no potential conflicts of interest with respect to the research, authorship, and/or publication of this article.

\section{Funding}

The author(s) disclosed receipt of the following financial support for the research, authorship, and/or publication of this article: This paper has been prepared in the framework of the research project "Local Conflict and the Local State" funded by the German Research Foundation (JU 2979/2-1).

\section{Supplemental Material}

Supplemental material for this article is available online.

\section{Notes}

1. Although all of our subsequent empirical analyses focus on protest only, we consider various forms of mobilization in the discussion of previous literature-in line with previous research indicating that they may actually be perceived as varying expressions of similar underlying political, economic, or social conditions (Tilly 2003).

2. Up until 2011, all of these countries had authoritarian regimes which were generally unwilling to release administrative data and authorize large scale public opinion data collection. Only Tunisia became a democratic regime and while a lot opinion data are being collected since 2011, South Africa's data availability remain unparalleled. For instance, the latest Tunisian census data were released in 2004 and crowd control data are - to the best of our knowledge — not collected in a detailed way.

3. Under Apartheid, there was full residential segregation with whites living in the town centers and the other groups being forcefully removed to dedicated townships. Large parts of the African population were moreover deported to so-called homelands residential segregation laws were revoked in the late 1980s, but the vastly different housing prices in these areas have left residential segregation intact in most townships.

4. We lose about 15 percent of the observations in each event period because of matching problems. Locations that cannot be matched to a police station are either those events that are reported at a higher level (e.g., Johannesburg) or in a subplace with a name that exists in more than one police station.

5. The results presented below are robust to using any of the access variables individually. These results are shown in Table A4.1 in the Online Appendix.

6. We use Stata's (Stata 12) user-written command "seg" by Sean F. Reardon with the "d" option to compute the index.

7. There is a general consensus in the literature on voting in South Africa that abstention is a signal of alienation from and dissatisfaction with the government (see discussion in Wegner 2016). This is why our measure of African National Congress support accounts for turnout. 
8. This information is only available at the municipal level which increases measurement error and biases estimates toward zero. We nevertheless believe that it is important to include some information about state capacity.

9. We exclude about fifty police districts that only contain one subplace and where inequality would therefore be zero. These cases are either police districts in large - metropolitanmunicipalities that have a high number of police districts or in rural areas where subplaces cover large spaces. We also exclude the police districts "without" events from the analysis rather than keeping them with a count of zero events. The reason is that a substantial number of these might have had protest that we were unable to match. However, the results remain robust to including these police stations with a count of zero. In addition, we lose a number of police stations that could not be matched to the electoral data.

10. This service inequality measure differs from the one introduced above because we are dealing with individual-level survey data rather than aggregated administrate data. However, it captures well the intuition behind our use of the dissimilarity index. Although the dissimilarity index assesses a police station's service inequality in absolute terms and the new measure in terms of a subplace's position relative to its neighbors, in both cases, we assume that they are those people at the lower end of the distribution who are engaging in protest.

11. Alternative nonlinear specifications for the protest variable generate similar results; results are available upon request.

12. The matching approach requires a binary treatment while our main explanatory variables are continuous. We have used a binary variable with the value "1" for all observations with inequality levels within the fourth quartile; control cases are limited to the first quartile to ensure sufficient difference in between treatment and control group.

13. We consider the data to be representative at the level of the police station if the difference in mean employment, access to trash removal, electricity, and sanitation and share of population groups was \pm 10 percent.

14. We use the user-written Stata command "Mahapick" (Kantor 2012) for this exercise.

15. Absolute values of all variables used for the matching process are presented for both cases in the Online Appendix (A3.5).

\section{References}

Al-Araby. 2015. "Lebanese Protesters Give Government Three-day Ultimatum." August 30. Accessed July 8, 2015. http://www.alaraby.co.uk/english/news/2015/8/30/lebanesegroups-threaten-to-escalate-protests.

Alexander, Peter. 2010. "Rebellion of the Poor: South Africa's Service Delivery Protests-A Preliminary Analysis." Review of African Political Economy 37 (123): 25-40.

Askvik, S., I. Jamil, and Tek Nath Dhakal. 2011. "Citizens' Trust in Public and Political Institutions in Nepal." International Political Science Review 32 (4): 417-37.

Atkinson, Doreen. 2007. "Taking to the Streets: Has Developmental Local Government Failed in South Africa." State of the Nation: South Africa 2007: 53-77.

Bega, Sheree. 2014a. "The Naked Truth about a Really Big Stink." Saturday Star, June 14. Bega, Sheree. 2014b. "Shame of Bucket-toilet Existence." Saturday Star, June 21. 
Benford, Robert D., and David A. Snow. 2000. "Framing Processes and Social Movements: An Overview and Assessment." Annual Review of Sociology 26:611-39.

Booysen, Susan. 2007. "With the Ballot and the Brick the Politics of Attaining Service Delivery." Progress in Development Studies 7 (1): 21-32.

Brinkerhoff, Derick W., Anna Wetterberg, and Stephen Dunn. 2012. "Service Delivery and Legitimacy in Fragile and Conflict-affected States." Public Management Review 14 (2): 273-93.

Buhaug, Halvard, Lars-Erik Cederman, and Kristian Skrede Gleditsch. 2014. "Square Pegs in Round Holes: Inequalities, Grievances, and Civil War.” International Studies Quarterly 58 (2): 418-31.

Collier, Paul, and Anke Hoeffler. 2004. "Greed and Grievance in Civil War." Oxford Economic Papers 56 (4): 563-95.

Cornell, Agnes, and Marcia Grimes. 2015. "Institutions as Incentives for Civic Action: Bureaucratic Structures, Civil Society, and Disruptive Protests." The Journal of Politics 77 (3): 664-78.

De Juan, Alexander, and Jan H. Pierskalla. 2015. "Manpower to Coerce and Co-opt—State Capacity and Political Violence in Southern Sudan 2006-2010." Conflict Management and Peace Science 32 (2): 175-99. doi:10.1177/0738894213520393.

De Visser, J., and D. Powell. 2012. "Service Delivery Protest Barometer 2007-2012." Cape Town: Multi-level Government Initiative, Community Law Centre [Online]. Accessed July 8, 2015. http://mlgi.org.za/barometers/service-delivery-protest-barometer.

DiPasquale, Denise, and Edward L. Glaeser. 1998. "The Los Angeles Riot and the Economics of Urban Unrest." Journal of Urban Economics 43 (1): 52-78.

Duncan, Otis Dudley, and Beverly Duncan. 1955. "A Methodological Analysis of Segregation Indexes." American Sociological Review 20 (2): 210-17.

Fearon, James D., and David D. Laitin. 2003. "Ethnicity, Insurgency, and Civil War.” American Political Science Review 97 (1): 75-90.

Gamson, William A. 1975. The Strategy of Social Protest. Homewood, IL: Dorsey Press.

Garman, Christopher, and Clifford Young. 2015. "Brazil's Protests Are Not Just about the Economy.” Reuters Blogs. Accessed July 8, 2015. http://blogs.reuters.com/great-debate/ 2013/06/21/brazils-protests-are-not-just-about-the-economy/.

Guerrero, Alejandro. 2011. Rebuilding Trust in Government via Service Delivery: The Case of Medellin, Colombia. Washington, DC: World Bank.

Gurr, Ted. 1970. Why Men Rebel. Princeton, NJ: Princeton University Press.

Harsch, Ernest. 2011. "Winding Path to Decent Housing for South Africa's Poor." Africa Renewal Online. (published June 17, 2011).

Hirsch, Jain. 2010. Community Protests in South Africa: Trends, Analysis and Explanations. Cape Town, South Africa: University of Cape Town.

Horrell, Muriel. 1973. A Survey of Race Relations in South Africa, Vol. 26. Los Angeles, CA. University of California Press.

Ige, K. D., and F. H. Nekhwevha. 2012. "Poverty Attribution in the Developing World: A Critical Discussion on Aspects of Split Consciousness among Low Income Urban Slum Dwellers in Lagos.” Journal of Social Sciences 33 (2): 213-26. 
Iyengar, Shanto. 1989. "How Citizens Think about National Issues: A Matter of Responsibility." American Journal of Political Science 33 (4): 878-900.

Javeline, Debra Lynn. 2009. Protest and the Politics of Blame: The Russian Response to Unpaid Wages. Ann Arbor: University of Michigan Press.

Kantor, David. 2012. "MAHAPICK: Stata Module to Select Matching Observations Based on a Mahalanobis Distance Measure." Software component provided by Boston College Department of Economics in its series Statistical Software Components with number S456703.

Khunou, Grace. 2002. "'Massive Cut Offs'-Cost Recovery and Electricity Service in Diepkloof, Soweto." In Massive Cut Offs Cost Recovery and Electricity Service in Diepkloof, Soweto, edited by David A. McDonald and John Pape, 61-77. London, UK: Zed Books.

Kluegel, James R., and Eliot R. Smith. 1986. Beliefs about Inequality: Americans' Views of What Is and What Ought to Be. Brunswick, NJ: Transaction.

Leibbrandt, Murray, Ingrid Woolard, A. Finn, and J. Argent. 2009. "Trends in South African Income Distribution and Poverty since the Fall of Apartheid." OECD Social, Employment and Migration Working Papers 101, Organisation for Economic Co-operation and Development (OECD), Paris, France.

Mabotja, Kgopi. 2015. "Fiery Power Protest in Freezing Joburg." The Star, June 18.

Mafukidze, Jonathan K., and Fazeela Hoosen. 2009. "Housing Shortages in South Africa: A Discussion of the After-effects of Community Participation in Housing Provision in Diepkloof." Urban Forum 20 (4): 379. doi:10.1007/s12132-009-9068-7.

Marx, K. [1847] 1935. Wage, Labour and Capital. New York: International.

McAdam, Doug, Sidney Tarrow, and Charles Tilly. 2001. Dynamics of Contention. Cambridge, MA: Cambridge University Press.

Meyer, David S. 2004. "Protest and Political Opportunities." Annual Review of Sociology 30 (1): 125-45.

Minister of Police, Republic of South Africa. 2010. "For Written Reply. Question No. 194, National Assembly of the Republic of South Africa [cited in Pfaffe, Peter 2011]. A Protest Event Analysis of South Africa's Rebellion of the Poor." Master thesis, Berlin School of Economics, Berlin, Germany, p. 14.

Mokati, Noni. 2011. "Diepkloof Hostel Residents Angry about Lack of Services.” Saturday Star, May 14.

Mtshazo, Xolile. 2013. "Frustration Boiling Over-Soweto Settlement Wants Better Life Now." Sunday World, April 28.

Murshed, S. Mansoob, and Scott Gates. 2005. "Spatial-Horizontal Inequality and the Maoist Insurgency in Nepal." Review of Development Economics 9 (1): 121-34.

Narayan-Parker, Deepa. 1997. Voices of the Poor: Poverty and Social Capital in Tanzania. Washington, DC: World Bank.

Netswera, Fulufhelo. 2005. "Local Government Service Provision and Non-payment within Underdeveloped Communities of the Johannesburg Unicity: Service Providers' and Consumers' Perspective." Thesis presented for the Degree of Doctor of Philosophy-Sociology of Development (DPhil) at the University of Stellenbosch, South Africa.

Oberschall, A. 1978. "Theories of Social Conflict." Annual Review of Sociology 4 (1): 291-315. 
Østby, Gudrun. 2008. "Polarization, Horizontal Inequalities and Violent Civil Conflict." Journal of Peace Research 45 (2): 143-62.

Østby, Gudrun. 2013. "Inequality and Political Violence: A Review of the Literature." International Area Studies Review 16 (2): 206-31.

Pellicer, Miquel, Patrizio Piraino, and Eva Wegner. 2014. "Information, Mobilization, and Demand for Redistribution: A Survey Experiment in South Africa." A Southern Africa Labour and Development Research Unit Working Paper Number 139, SALDRU, University of Cape Town, South Africa.

Rubin, Margot. 2008. Land Management and Democratic Governance in the City of Johannesburg. Johannesburg, South Africa: Centre for Urban and Built Environment Studies (CUBES).

Runciman, Walter Garrison. 1966. Relative Deprivation and Social Justice: A Study of Attitudes to Social Inequality in Twentieth-century England. Berkeley, CA: University of California Press.

Salehyan, Idean, Cullen S. Hendrix, Jesse Hamner, Christina Case, Christopher Linebarger, Emily Stull, and Jennifer Williams. 2012. "Social Conflict in Africa: A New Database." International Interactions 38 (4): 503-11. doi:10.1080/03050629.2012.697426.

SANews.gov.za. 2013. Census Results on Service Delivery Surprising. Accessed July 8, 2015. http://www.sanews.gov.za/south-africa/census-results-service-delivery-surprising.

Seawright, Jason, and John Gerring. 2008. "Case Selection Techniques in Case Study Research: A Menu of Qualitative and Quantitative Options." Political Research Quarterly 61 (2): 294-308.

Selzer, Amy. 2012. "Enhancing Capabilities or Delivering Inequality? Contestation and Service Delivery in Urban South Africa." Submitted in partial fulfillment of the requirement for the degree of Doctor of Philosophy in the Department of Sociology at Brown University, Providence, RI.

Serino, Kenichi. 2014. "South Africa's Wave of Discontentment-Al Jazeera English.” Aljazeera, March 20. Accessed July 8, 2015. http://www.aljazeera.com/indepth/features/2014/ 03/south-africa-wave-discontentment-2014312131838235849.html.

Shepelak, Norma J., and Duane F. Alwin. 1986. "Beliefs about Inequality and Perceptions of Distributive Justice." American Sociological Review 51 (1): 30-46.

Siyotula, Uyanda. 2014. "Bare Bums Call for Service Delivery." The Daily Vox. June 26. Accessed July 8, 2015. http://www.thedailyvox.co.za/bare-bums-call-for-service-delivery/.

Skocpol, Theda. 1979. States and Social Revolutions: A Comparative Analysis of France, Russia and China. Cambridge, MA: Cambridge University Press.

Smith, Heather J., Thomas F. Pettigrew, Gina M. Pippin, and Silvana Bialosiewicz. 2012. "Relative Deprivation A Theoretical and Meta-analytic Review." Personality and Social Psychology Review 16 (3): 203-32.

Smith, Kevin B., and Lorene H. Stone. 1989. "Rags, Riches, and Bootstraps: Beliefs about the Causes of Wealth and Poverty." The Sociological Quarterly 30 (1): 93-107.

Stewart, Frances. 2000. "Crisis Prevention: Tackling Horizontal Inequalities." Oxford Development Studies 28 (3): 245-62. 
Stewart, Frances. 2002. "Horizontal Inequalities: A Neglected Dimension of Development." Queen Elizabeth House Working Paper Series-QEHWPS81, University of Oxford, UK. Tilly, Charles. 1978. From Mobilization to Revolution. New York: McGraw-Hill.

Tilly, Charles. 2003. The Politics of Collective Violence. Cambridge, UK: Cambridge University Press.

van der, Toorn, Jojanneke, Matthew Feinberg, John T. Jost, Aaron C. Kay, Tom R. Tyler, Robb Willer, and Caroline Wilmuth. 2015. "A Sense of Powerlessness Fosters System Justification: Implications for the Legitimation of Authority, Hierarchy, and Government." Political Psychology 36 (1): 93-110.

van Dyke, Nella, Sarah A. Soule, and Verta A. Taylor. 2004. "The Targets of Social Movements: Beyond a Focus on the State." In Authority in Contention, vol. 25, 27-51. Research in Social Movements, Conflicts and Change 25. Bingley, UK: Emerald Group.

van Zomeren, Martijn, Tom Postmes, and Russell Spears. 2008. "Toward an Integrative Social Identity Model of Collective Action: A Quantitative Research Synthesis of Three Socio-psychological Perspectives." Psychological Bulletin 134 (4): 504-35.

Yu, Weiyu, Robert E. S. Bain, Shawky Mansour, and Jim A. Wright. 2014. “A Cross-sectional Ecological Study of Spatial Scale and Geographic Inequality in Access to Drinking-water and Sanitation." International Journal for Equity in Health 13 (1): 113.

Walker, Edward T., Andrew W. Martin, and John D. McCarthy. 2008. "Confronting the State, the Corporation, and the Academy: The Influence of Institutional Targets on Social Movement Repertoires." American Journal of Sociology 114 (1): 35-76.

Wegner, Eva. 2016. "Local-level Accountability in a Dominant Party System." Government and Opposition, 1-25. doi:10.1017/gov.2016.1. 